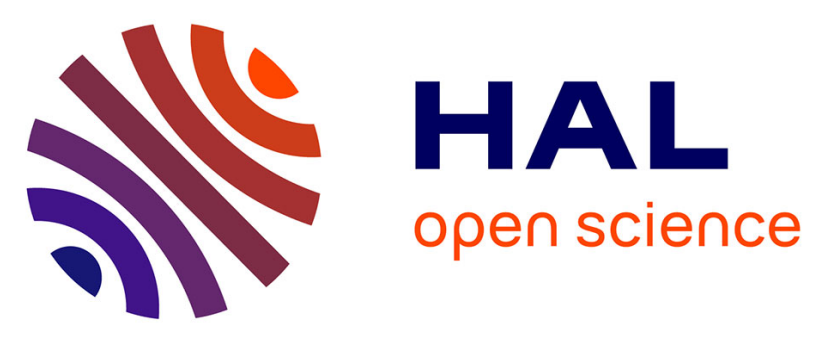

\title{
Synthesis, structure, magnetic and luminescence properties of two dysprosium single-molecule magnets based on phenoxide dye ligands
}

Jérome Long, Alexander Selikhov, Ekaterina Mamontova, Konstantin A. Lyssenko, Yannick Guari, Joulia Larionova, Alexander A. Trifonov

\section{To cite this version:}

Jérome Long, Alexander Selikhov, Ekaterina Mamontova, Konstantin A. Lyssenko, Yannick Guari, et al.. Synthesis, structure, magnetic and luminescence properties of two dysprosium singlemolecule magnets based on phenoxide dye ligands. CrystEngComm, 2020, 22 (11), pp.1909-1913. 10.1039/D0CE00055H . hal-02527755

\section{HAL Id: hal-02527755 \\ https://hal.science/hal-02527755}

Submitted on 26 Nov 2020

HAL is a multi-disciplinary open access archive for the deposit and dissemination of scientific research documents, whether they are published or not. The documents may come from teaching and research institutions in France or abroad, or from public or private research centers.
L'archive ouverte pluridisciplinaire HAL, est destinée au dépôt et à la diffusion de documents scientifiques de niveau recherche, publiés ou non, émanant des établissements d'enseignement et de recherche français ou étrangers, des laboratoires publics ou privés. 


\title{
Synthesis, structure, magnetic and luminescent properties of two dysprosium Single-Molecule Magnets based on phenoxide dye ligands.
}

\author{
Jérôme Long* , ${ }^{a}$ Alexander N. Selikhov, ${ }^{b, c}$ Ekaterina Mamontova, ${ }^{a}$ Konstantin A. Lyssenko, ${ }^{c, d}$ \\ Yannick Guari, ${ }^{a}$ Joulia Larionova, ${ }^{a}$ and Alexander A. Trifonov* ${ }^{b, c}$
}

We report here two dysprosium complexes based on phenoxidebased emissive ligands 1-(2,4-dimetylphenylazo)-2-naphtholate (L1) and anthracenolate (L2). While 1 is a dinuclear homoleptic complex $\left[\mathrm{Dy}_{2}(\mathrm{~L} 1)_{6}\right] \cdot 2 \mathrm{C}_{7} \mathrm{H}_{8}$ exhibiting a zero-field slow relaxation of the magnetization, 2 is a mononuclear complex $\left[\mathrm{Dy}(\mathrm{L} 2)_{3}(\mathrm{py})_{3}\right]$ (py $=$ pyridine) showing a field-induced relaxation.

Lanthanide-based complexes have been extensively studied for the last fifteen years due to their impressive magnetic properties that give rise to the appearance of a slow relaxation of the magnetization and so-called Single-Molecule Magnet (SMM) behaviour, which finds potential applications in highdensity information storage or quantum computing. ${ }^{1-4}$ Yet, such expectations require to efficiently optimize the magnetic properties of the complexes by controlling the magnetic anisotropy through a modulation of the lanthanide ions' coordination environment. Indeed, in such systems, the high magnetic anisotropy of certain lanthanide ions may be exacerbated in a specific ligand environment/symmetry to provide a large crystal-field splitting and in turn generate a large anisotropic barrier, $\Delta$, separating two opposite magnetic states. Hence, the presence of dominated thermally activated relaxation (or Orbach relaxation) might result in the appearance of the SMM behaviour. One of the main challenges in the field is dedicated to increase the anisotropic barriers and the blocking temperatures. ${ }^{5-6}$ Despite the fact that other processes, such as the Quantum Tunnelling of the Magnetization (QTM), direct or Raman relaxations may create their own relaxation pathways therefore decreasing the effective energy barrier, simple electrostatic considerations provide a synthetic strategy based on the optimal alliance between the electronic density of specific $4 f$ lanthanide ions (oblate or prolate) and the crystal-field imposed by the ligand environment (axial or equatorial). ${ }^{7}$ Following this approach, numerous lanthanide complexes with high anisotropic barriers of few thousands of wavenumbers have been recently reported, ${ }^{5,-11}$ while a series of dysprosium metallocene complexes has demonstrated the best magnetic properties with the highest energy barriers and hysteresis ${ }^{10,12-13}$ at temperatures that even exceed liquid nitrogen boiling temperature. ${ }^{14}$ The majority of the aforementioned examples belong to organometallic complexes involving cyclopentadienyl derivatives $\left(C p^{R}\right)$ providing linear $C p^{R}-D y-C p^{R}$ angles, short $\mathrm{Dy}-\mathrm{C} \mathrm{p}^{\mathrm{R}}$ distances in axial positions and the lack of ligands in equatorial positions, which generates a strong axial crystal-field maximizing the anisotropy. ${ }^{12-14}$ Using such route with coordination ligands involving nitrogen or oxygenlanthanide bonds appears however more intricate.

On the other hand, although exchange interactions between lanthanide ions in SMMs are commonly considered as weak with respect to the dominating single-ion anisotropy, their role is not yet clearly understood. ${ }^{15}$ Different literature examples have demonstrated a decrease of the anisotropy barrier in polynuclear $\mathrm{Dy}^{3+}$ based complexes due to the mixing of the states and/or QTM increase. ${ }^{16}$ However, several cases show also a positive impact of the magnetic interactions caused by an exchange bias effect that shifts the usual zerofield QTM relaxation, ${ }^{17-20}$ that could eventually lead to a large magnetic coercivity. ${ }^{21}$ Obviously, dinuclear complexes represent therefore the simplest model to study the influence of exchange interactions over the slow relaxation dynamics. ${ }^{22}$ In this sense, one strategy consists in employing bulky phenoxide ligands in the axial position that ensure $\mathrm{Ln}-\mathrm{O}$ short distances, ${ }^{8,23-25}$ and potentially bridge lanthanide ions. In addition, such ligands may be appropriate to implement additional functionalities, such as luminescence. ${ }^{26-28}$ With this in mind, numerous dyes incorporating phenoxide moieties may be used as ligands for the design of luminescent SMMs. ${ }^{26 \text {, }}$ 28-29

Following this idea, we report in this communication the synthesis, structure, magnetic and luminescent studies of two dysprosium complexes showing different nuclearities and based on two phenoxide dye ligands. Remarkably, the dinuclear complex reveals a zero-field slow relaxation reflecting a genuine SMM behaviour, while the mononuclear exhibits a field-induced slow relaxation.

Firstly, the reaction of $\mathrm{Dy}\left[\mathrm{N}\left(\mathrm{SiMe}_{3}\right)_{2}\right]_{3}$ with three equivalents of 1-(2,4-dimetylphenylazo)-2-naphthol (orange dye Sudan-II), in toluene at $60{ }^{\circ} \mathrm{C}$ expectedly affords a homoleptic dinuclear naphtholate complex $\left[\mathrm{Dy}_{2}(\mathrm{~L} 1)_{6}\right] \cdot 2 \mathrm{C}_{7} \mathrm{H}_{8} \quad$ (1) (Scheme 1 ). Recrystallization from cold toluene resulted in the isolation of the complex as bright-orange moisture and air sensitive $\mathbf{1}$ crystals in $90 \%$ yield. Dissolution of $\mathbf{1}$ in THF does not lead to its dissociation and the dimeric structure of the complex remains retained after recrystallization from a mixture of THFhexane. Secondly, reaction of anhydrous $\mathrm{DyCl}_{3}$ with potassium anthracenolate was carried out in a pyridine solution at $80{ }^{\circ} \mathrm{C}$ (Scheme 1). Yellow crystals of complex $\left[\mathrm{Dy}(\mathrm{L} 2)_{3}(\mathrm{py})_{3}\right](2)$ were 
obtained by slow diffusion of hexane into a solution of the complex in pyridine.

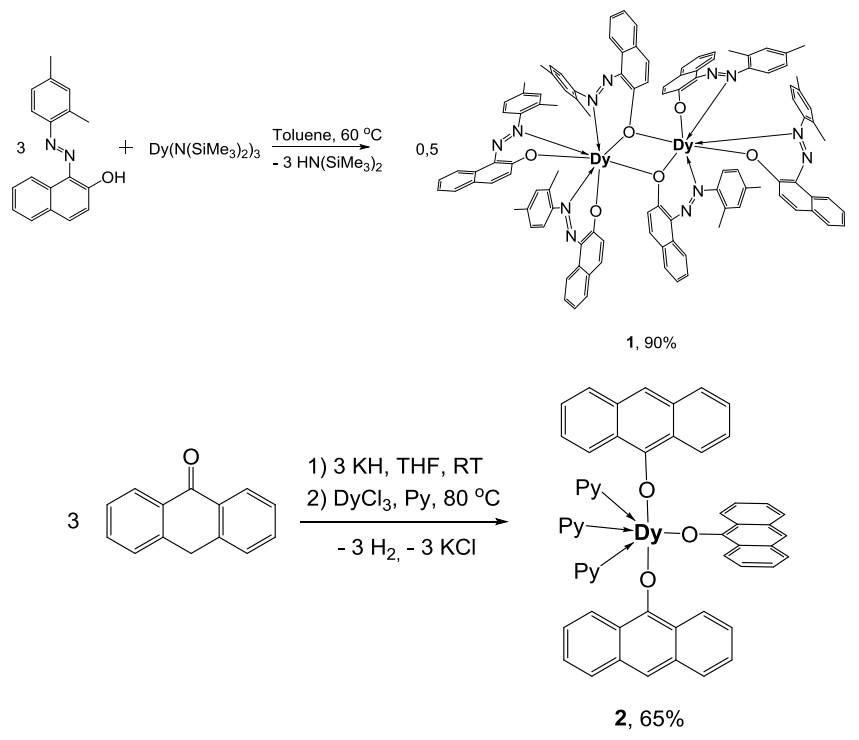

Scheme 1. Synthesis of complexes 1 and $\mathbf{2}$.

The single-crystal X-ray diffraction studies reveal that complex 1 crystallizes in the triclinic $P \overline{1}$ space group with 2 molecules of toluene $\left(1 \bullet 2 \mathrm{C}_{7} \mathrm{H}_{8}\right)$ as a solvate (Table $\left.\mathrm{S} 1\right)$. The asymmetric unit contains two crystallographically independent dinuclear complexes (one of those is shown in Fig. 1 and another in Fig S1, ESI) both located in the center of symmetry. Each dysprosium is coordinated by three $\mathrm{N}, \mathrm{O}-\mathrm{K}^{2}$ chelating naphtholate ligands; two of them are terminal, while one is $\mu^{2}$ bridging two $\mathrm{Dy}^{3+}$ centers via phenolate oxygen. Hence, each $\mathrm{Dy}^{3+}$ ion is seven-coordinated and surrounded by four naphtholate oxygen atoms of four ligands and three nitrogen atoms of $-\mathrm{N}=\mathrm{N}-$ azo groups. Each dysprosium site was analyzed by the SHAPE ${ }^{30}$ software that indicates a capped octahedron geometry (Table S2). The intramolecular Dy1-Dy1 and Dy2-Dy2 distances are equal to 3.8442(11) and 3.818(1) $\AA$ respectively, while the bridging angles Dy-O-Dy are $110.2(2)^{\circ}$ and $109.0(2)^{\circ}$. These data are in a good agreement with the distances found in the previously described dinuclear phenolate dysprosium complexes with a similar structure and coordination environment. ${ }^{17,31}$ a)
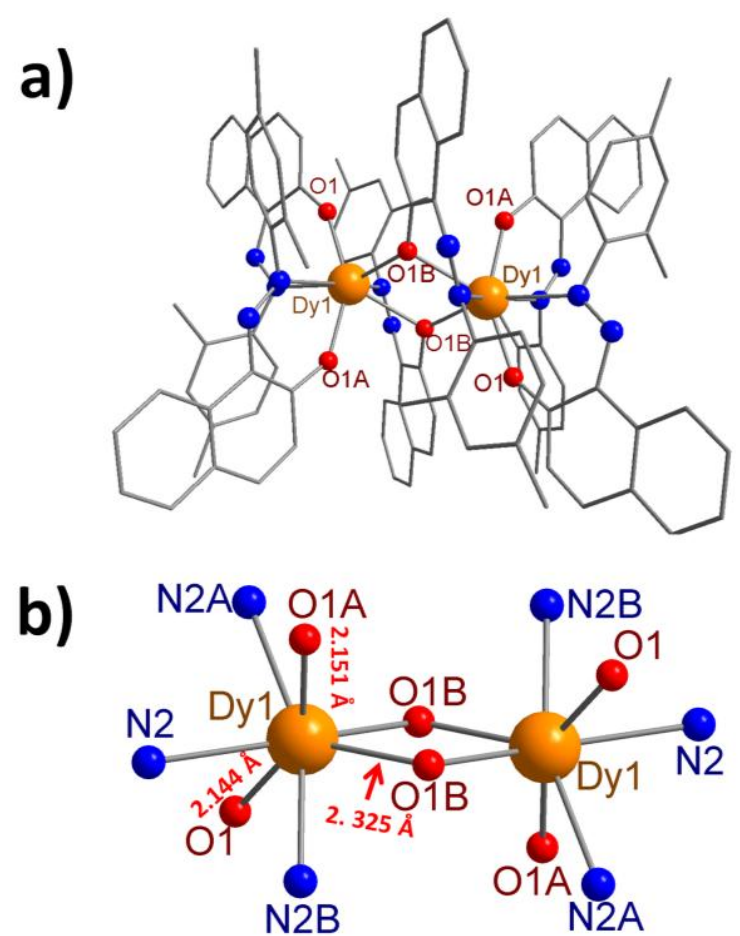

c)

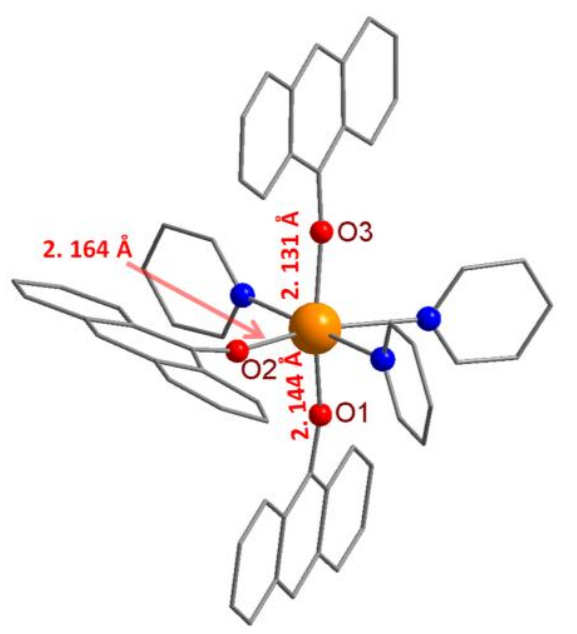

Fig. 1. a) Molecular structure of one of the two crystallographically independent dinuclear complexes in 1. b) View of one of the centrosymmetric dinuclear core in 1. c) molecular structure of the mononuclear complex 2 . Colour code: orange, Dy; blue, $\mathrm{N}$; grey, C; Hydrogen atoms have been omitted for clarity.

The 01-Dy1-O1A angle is equal to $150^{\circ}$ with short distances of Dy1-O1= 2.144(6) $\AA$ /Dy1-O1A = 2.151(8) $\AA$. These latter are expectedly shorter compared to the equatorial distances involving the $\mu^{2}$-bridging oxygen with Dy1-O1B distance of 2.325(8) A. The second crystallographic complex exhibits comparable distances and bond lengths with a O1C-Dy2-O1E angle of $147^{\circ}$ and distances Dy2-O1C $=2.157(6) \AA ̊ ․ / D y 2-O 1 E=$ 2.160(6) $\AA$ in the axial direction, while the equatorial Dy2-O1D distance is equal to 2.365 (9) $\AA$ (Fig. S1). In contrast, 2 could be described as a mononuclear complex with a unique crystallographic complex. This structure is similar to that of the previously described 2,6-diisopropyl- and 2,6-dimethylphenoxide complexes of $\mathrm{Dy}^{32}$ The $\mathrm{Dy}^{3+}$ adopts a distorted octahedron geometry (Table S2) and is coordinated by three monoanionic anthracenolate ligands and three pyridine 
molecules. The aryloxy ligands and pyridine localization yields to the meridional isomer of the octahedral complex. The Dy-O bond lengths are 2.131(3), 2.144(3), 2.164(3) ^, with an average value of $2.146 \AA$, which is in good agreement with the values described for other $\mathrm{Dy}^{3+}$ phenoxide derivatives. ${ }^{32}$ Noticeably, the two shortest Dy-O1 and Dy-O3 distances are located in the axial direction (in trans position) and forms an angle O1-Dy-O3 of $161.1(1)^{\circ}$. The lengths of the Dy-N bonds are largely longer with values ranging from $2.490(4)$ to 2.591(4) A. For both complexes, the crystal packing analysis reveals that the shortest intermolecular Dy-Dy distances are equal to $13.328(3)$ and 9.2020(7) $\AA$, for 1 and 2, respectively (Fig. S2). These values suggest that whereas the dinuclear complexes are relatively well isolated, the presence of intermolecular interactions may be expected for $\mathbf{2}$.

The magnetic properties were investigated in both, static (direct current (dc)) and dynamic (alternating current (ac)) modes by using a SQUID MPMS-XL. At room temperature, the $\chi^{T}$ values of 27.84 and $13.30 \mathrm{~cm}^{3} \cdot \mathrm{K} \mathrm{mol}^{-1}$ for $\mathbf{1}$ and $\mathbf{2}$, respectively, are in a relatively good accordance with the expected values of $28.34 \mathrm{~cm}^{3} \cdot \mathrm{K} \cdot \mathrm{mol}^{-1}$ and $14.17 \mathrm{~cm}^{3} \cdot \mathrm{K} \cdot \mathrm{mol}^{-1}$ $\left({ }^{6} \mathrm{H}_{15 / 2}\right)$ for either two non-interacting $\mathrm{Dy}^{3+}$ ions or a single $\mathrm{Dy}^{3+}$ ion. Lowering the temperature results in a monotonous decrease of $\chi^{T}$ due to the thermal depopulation of the $m_{\mathrm{J}}$ levels (Fig. S3). Yet, the pronounced $\chi T$ decrease for 1 rather suggests antiferromagnetic interactions between the $\mathrm{Dy}^{3+}$ ions. The field dependence of the magnetization at $1.8 \mathrm{~K}$ reveals a rapid increase of the magnetization as a function of field with the values of 12.64 and $5.53 N \beta$ under a $70 \mathrm{kOe}$ field for $\mathbf{1}$ and 2, respectively (Fig. S3).

The occurrence of a slow relaxation of the magnetization was investigated by ac measurements. Under a zero-dc field, both 1 and $\mathbf{2}$ exhibit a significant out-of-phase susceptibility $\left(\chi^{\prime \prime}\right)$ component but only 1 shows a maximum of $\chi^{\prime \prime}$ in our experimental conditions (Fig. S4). The frequency dependence of $\chi^{\prime \prime}$ for 1 reveals the presence of a temperature dependent single peak (Fig. 2). Despite the presence of two crystallographic dysprosium sites for $\mathbf{1}$, the fitting of the ColeCole plots (Fig. S5) with a generalized Debye model yields to relatively low values of the $\alpha$ parameter (i.e. $<0.3$ ) at low temperature, indicating a moderate distribution of relaxation times (Table S3). From these data, the relaxation time, $\tau$, could be extracted in order to analyse the relaxation dynamics. The $\ln \tau$ vs. $T$ plot (Fig. 3) reveals a deviation from the linearity at low temperature indicating a divergence from a thermally activated process. The whole data range could be modelled using the following equation: $\tau^{-1}=\tau_{0}{ }^{-1} \exp (-\Delta / k T)+C T^{m}+\tau$ ${ }^{-1}$ QTM (Eq. 1). ${ }^{33}$ The first term accounts for a thermally activated process, while the second and third ones stand for twophonon Raman and QTM, respectively. To avoid overparameterization, the $m$ coefficient was fixed to different values until getting the best correlation coefficient. It turns out that the magnetization relaxes through a combination of these three relaxation processes with a modest $\Delta$ value of $24 \pm 5$ $\mathrm{cm}^{-1}$ (Table 1). It could be noticed that a poor fitting in the low temperature range is observed with a large deviation for the QTM constant. This may be ascribed either to the presence of two dysprosium sites or the effect of the magnetic interactions between $\mathrm{Dy}^{3+}$ ions. Besides, a strong contribution from the Raman process should be underlined.

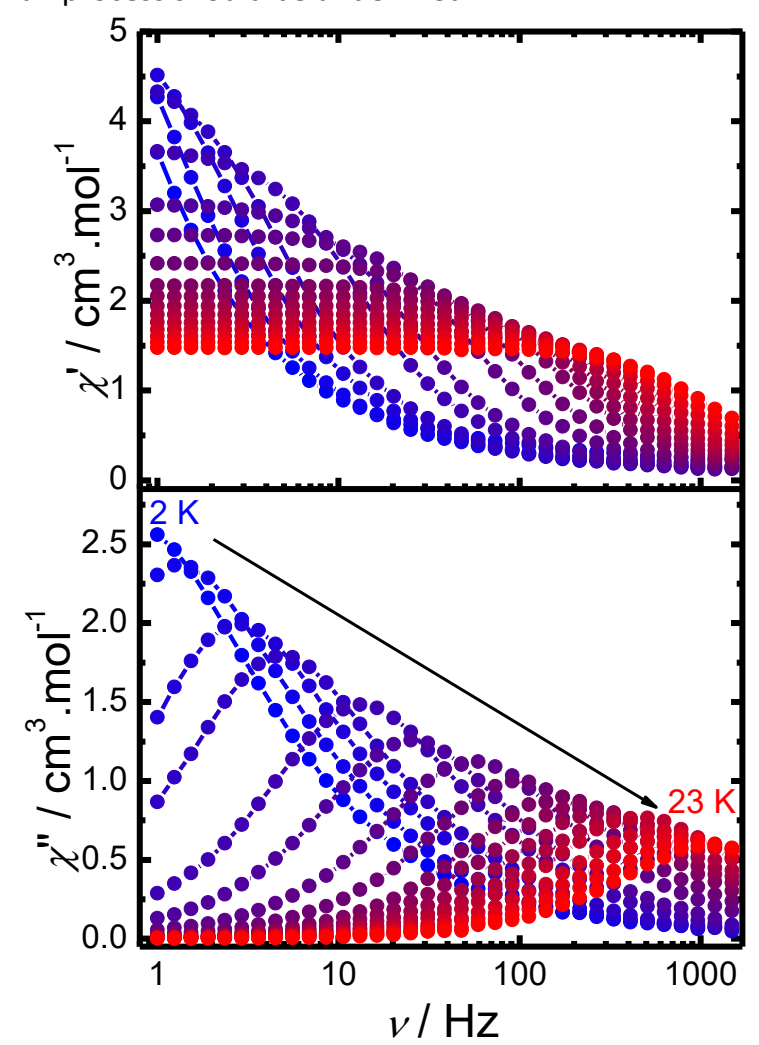

Fig. 2. Frequency dependence of $\chi^{\prime}$ and $\chi^{\prime \prime}$ for 1 under a zero dc-field.

With the aim to shortcut the QTM, ac measurements were performed under static dc-fields for both complexes $\mathbf{1}$ and $\mathbf{2}$ (Fig. S6). The field dependence of the relaxation time for $\mathbf{2}$ (Fig. S7) could be modelled with the usual equation $\tau^{-1}=D H^{4} T+$ $B_{1} /\left(1+B_{2} H^{2}\right)+K$ (Eq. 2), for which the first term accounts for the direct process (for Kramers-ion), the second one stands for the QTM, while the $K$ constant accounts for the fieldindependent Raman and thermally activated processes (Table S4). For 1, the optimum field could be estimated at 500 Oe. However, it could be noticed that the relaxation time is almost field-independent up to 2000 Oe and it was not possible to model the field dependence of the relaxation time which may be related to the presence of two dysprosium sites. This fieldindependent character may also suggest that magnetic interactions could shortcut in some extent the QTM as observed in other dinuclear complexes. ${ }^{17}$ On the contrary, Eq. 2 permits to nicely fit the $\tau$ vs. $H$ curve for $\mathbf{2}$ showing an optimal magnetic field between 1000 and 2000 Oe (Fig. S7). The frequency dependence of the ac susceptibilities and related Cole-Cole plots under the corresponding optimal dc fields still show a single relaxation process for both complexes (Fig. S8-S9, Table S5-S6). The temperature dependence of $\tau$ was also modelled by taking into account an additional direct process: $\tau^{-1}=\tau_{0}^{-1} \exp (-\Delta / k T)+C T^{m}+A T^{n}$ (Eq. 4, Table 1, Fig. 3) giving the $\Delta$ values of $34 \pm 1$ and $30 \pm 1 \mathrm{~cm}^{-1}$ for $\mathbf{1}$ and $\mathbf{2}$, respectively. 
Further insights could be obtained by determining the direction of the anisotropic axes of the ground doublet in both complexes with the MAGELLAN package. ${ }^{34}$ For the two dinuclear complexes in $\mathbf{1}$ and owing to the centrosymmetric character, the anisotropic axes of both Dy sites are found identical and are almost collinear to the two shortest Dy-O distances involving the terminal phenoxide moieties (Fig. S10) with a deviation of $8^{\circ}$ from the shortest Dy1-01 bond of 2.144(6) $\AA$ and $14^{\circ}$ from the second shortest Dy1-O1A bond of 2.151(8) A. The second dinuclear complex shows comparable deviation angle of 9.85 and $14.75^{\circ}$. Hence the electrostatic contributions are mainly dominated by these two negatively charged oxygens, while the bridging phenoxide oxygens located at longer distances (ranging from 2.311 to $2.375 \AA$ ) do not induce a strong deviation of the anisotropic axis. This results in the presence of an axial crystal-field suitable to stabilize the oblate electronic density of each Dy ${ }^{3+}$ sites $^{7}$ and, probably with a non-detrimental or positive impact of the magnetic interactions between the two $\mathrm{Dy}^{3+}$ ions that can explain the appearance of a slow magnetic relaxation in zerofield. Nevertheless, the absence of an opening in the hysteresis loop at $1.8 \mathrm{~K}$ in our experimental conditions (Fig. S11) for $\mathbf{1}$, suggests that the magnetic interactions between the Dy(III) ions are not strong enough to provide an exchange bias system that may greatly shortcut the zero-field QTM.

As regards 2, the anisotropic axis is almost collinear to the two shortest $\mathrm{Dy}-\mathrm{O} 3$ and $\mathrm{Dy}-\mathrm{O} 1$ bonds located in trans position (distances of 2.131 and $2.144 \AA$, Fig. S10) with deviation angles of 6.63 and $7.23^{\circ}$. On the other hand, the equatorial oxygen $\mathrm{O} 2$ is located almost perpendicularly (O1-Dy-O2 $=97.8^{\circ}$ and O3-Dy-O2 $=98.8^{\circ}$ ) with a relatively short distance of $2.164 \AA$. This explains the occurrence of a transverse component leading to a strong QTM and in turn the need to use a static dc field to reveal the maximum of $\chi^{\prime \prime}$. It could be however highlighted that despite the presence of relatively short Dy-O distances, the anisotropic barriers for $\mathbf{1}$ and $\mathbf{2}$ are found relatively weak, suggesting a major influence of the Raman relaxation process as deduced from the fitting of the temperature dependence of the relaxation time.

Moreover, phenolate-based ligands are also appropriate to implement luminescence properties in order to design luminescent SMMs. ${ }^{26-27}$ At room temperature and solid-state, both, 1 and $\mathbf{2}$ exhibit a broad ligand-based emission band located at with different emissions located at 615 and $550 \mathrm{~nm}$, respectively (Fig. S12).
Table 1: Fit parameters of the temperature dependence of the relaxation time for 1 and 2.

\begin{tabular}{|c|c|c|c|c|c|c|}
\hline Compound & $\begin{array}{c}\Delta \\
\left(\mathrm{cm}^{-1}\right)\end{array}$ & $\tau_{0}(\mathrm{~s})$ & $m$ & $\begin{array}{c}C \\
\left(\mathrm{~s}^{-1} \cdot \mathrm{K}^{-m}\right)\end{array}$ & $\tau_{\text {QTM }}(\mathrm{s})$ & $\begin{array}{c}A \\
\left(\mathrm{~s}^{-1} \cdot \mathrm{K}^{1}\right)\end{array}$ \\
\hline $\mathbf{1}(0 \mathrm{Oe})$ & $24 \pm 5$ & $\begin{array}{c}(3 \pm 2) \times \\
10^{-4}\end{array}$ & $4.8^{*}$ & $\begin{array}{c}0.00184 \\
\pm \\
0.00004\end{array}$ & $\begin{array}{c}0.08 \pm \\
0.14\end{array}$ & - \\
\hline $\mathbf{1}(500 \mathrm{Oe})$ & $34 \pm 1$ & $\begin{array}{c}(4.6 \pm 0.5) \\
\times 10^{-6}\end{array}$ & $6.5^{*}$ & $\begin{array}{c}(6.4 \pm \\
0.1) \times \\
10^{-7}\end{array}$ & - & - \\
\hline $\mathbf{2}(1000$ & $30 \pm 1$ & $\begin{array}{c}(2.7 \pm 0.4) \\
\times 10^{-6}\end{array}$ & $5^{*}$ & $\begin{array}{c}0.0045 \\
\pm\end{array}$ & - & $1 \pm 1$ \\
\hline
\end{tabular}

* fixed parameter

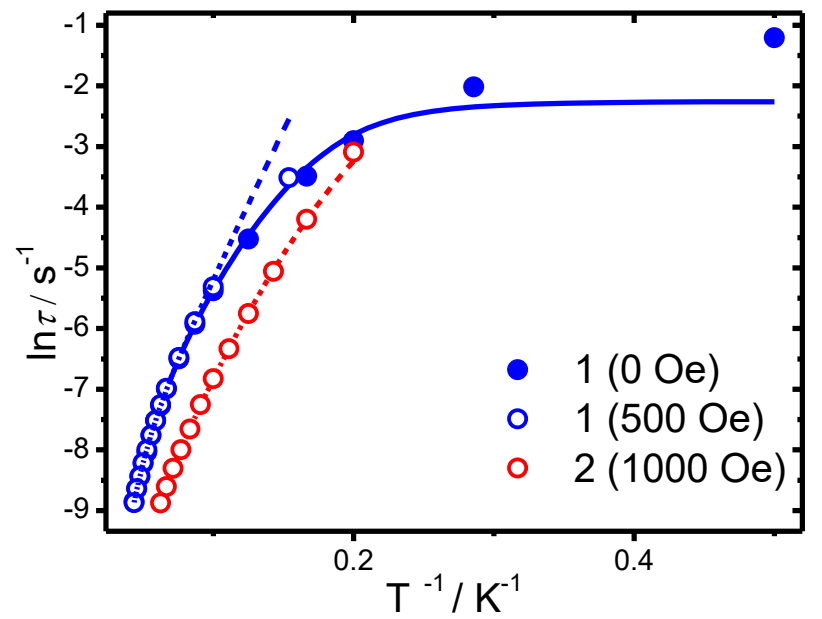

Fig. 3. Temperature dependence of the relaxation time for $1(0$ and $500 \mathrm{Oe})$ and 2 $(1000$ Oe) using the ac susceptibility data. The solid line represents the fit with Eq. 1 (0 Oe) and dashed lines with Eq. 3.

In summary, we have described in this communication two dysprosium complexes using different phenoxide-based dyes. Thus, in the homoleptic dinuclear complexes $\mathbf{1}$, the relatively short Dy-O distances in the axial position and a relatively wide O-Dy-O angle of $147-150^{\circ}$ create an axial crystal-field for each $\mathrm{Dy}^{3+}$ site. This promising axiality and the non-deleterious impact of the magnetic interactions between the two $\mathrm{Dy}^{3+}$ are suitable to provide a zero-field slow relaxation of the magnetization observed for this compound and offers a nice example of a dinuclear Dy-based genuine SMM behaviour. On the other hand, the mononuclear complex shows only a fieldinduced SMM behaviour due to the presence of a phenolate ligand with the short Dy-O bond in the equatorial plane, which certainly decreases the axiality. In both cases, the influence of the Raman relaxation seems to be important and explain the presence of a relatively low energy barriers. Depending on the ligand's nature, a drastic change in the emission properties of the resulting complexes is observed. Consequently, the large tunability of such ligands in (steric and electronic) should provide facile experimental means to adjust and improve both the slow relaxation features and optical properties.

The authors thank the University of Montpellier, CNRS for financial support, PAC of ICGM for magnetic measurements and the Analytical Center of The G.A. Razuvaev IOMC RAS for the X-ray study. The Russian co-authors thank the Russian 
Science Foundation (grant 17-73-30036). The X-ray study of has been carried out in the framework of the Russian state assignment (Theme № 44.2, Reg. № AAAA-A16116122110053-1) using the equipment of The Analytical Center of IOMC RAS.

\section{Conflicts of interest}

There are no conflicts to declare.

\section{Notes and references}

1 J. Luzon and R. Sessoli, Dalton Trans., 2012, 41, 13556-13567.

2 D. N. Woodruff, R. E. P. Winpenny and R. A. Layfield, Chem. Rev., 2013, 113, 5110-5148.

3 F. Troiani and M. Affronte, Chem. Soc. Rev., 2011, 40, 31193129.

4 L. Bogani and W. Wernsdorfer, Nat. Mater., 2008, 7, 179-186.

5 L. Ungur and L. F. Chibotaru, Inorg. Chem., 2016, 55, 1004310056.

6 J.-L. Liu, Y.-C. Chen and M.-L. Tong, Chem. Soc. Rev., 2018, 47, 2431-2453.

7 J. D. Rinehart and J. R. Long, Chem. Sci., 2011, 2, 2078-2085.

8 J. Liu, Y.-C. Chen, J.-L. Liu, V. Vieru, L. Ungur, J.-H. Jia, L. F. Chibotaru, Y. Lan, W. Wernsdorfer, S. Gao, X.-M. Chen and M.-L. Tong, J. Am. Chem. Soc., 2016, 138, 5441-5450.

9 S. K. Gupta, T. Rajeshkumar, G. Rajaraman and R. Murugavel, Chem. Sci., 2016, 7, 5181-5191.

10 F. S. Guo, B. M. Day, Y. C. Chen, M. L. Tong, A. Mansikkamaki and R. A. Layfield, Angew. Chem. Int. Ed. Engl., 2017, 56, 11445 11449.

11 Y.-S. Ding, N. F. Chilton, R. E. P. Winpenny and Y.-Z. Zheng, Angew. Chem. Int. Edit., 2016, 55, 16071-16074.

12 C. A. P. Goodwin, F. Ortu, D. Reta, N. F. Chilton and D. P. Mills, Nature, 2017, 548, 439-442.

13 K. Randall McClain, C. A. Gould, K. Chakarawet, S. J. Teat, T. J. Groshens, J. R. Long and B. G. Harvey, Chem. Sci., 2018, 9, 8492 8503.

14 F.-S. Guo, B. M. Day, Y.-C. Chen, M.-L. Tong, A. Mansikkamäki and R. A. Layfield, Science, 2018, 362, 1400-1403.

15 M. J. Giansiracusa, E. Moreno-Pineda, R. Hussain, R. Marx, M. Martínez Prada, P. Neugebauer, S. Al-Badran, D. Collison, F. Tuna, J. van Slageren, S. Carretta, T. Guidi, E. J. L. McInnes, R. E. P. Winpenny and N. F. Chilton, J. Am. Chem. Soc., 2018, 140 2504-2513.

16 R. J. Blagg, L. Ungur, F. Tuna, J. Speak, P. Comar, D. Collison, W. Wernsdorfer, E. J. L. McInnes, L. F. Chibotaru and R. E. P. Winpenny, Nat. Chem., 2013, 5, 673-678.

17 J. Long, F. Habib, P.-H. Lin, I. Korobkov, G. Enright, L. Ungur, W. Wernsdorfer, L. F. Chibotaru and M. Murugesu, J. Am. Chem. Soc., 2011, 133, 5319-5328.

18 K. Katoh, R. Asano, A. Miura, Y. Horii, T. Morita, B. K. Breedlove and M. Yamashita, Dalton Trans., 2014, 43, 7716-7725.

19 E. M. Pineda, Y. Lan, O. Fuhr, W. Wernsdorfer and M. Ruben, Chem. Sci., 2017, 8, 1178-1185.

20 J. Xiong, H.-Y. Ding, Y.-S. Meng, C. Gao, X.-J. Zhang, Z.-S. Meng, Y.-Q. Zhang, W. Shi, B.-W. Wang and S. Gao, Chem. Sci., 2017, 8, 1288-1294.

21 J. D. Rinehart, M. Fang, W. J. Evans and J. R. Long, Nat. Chem., 2011, 3, 538-542.
22 F. Habib and M. Murugesu, Chem. Soc. Rev., 2013, 42, 32783288.

23 Y.-C. Chen, J.-L. Liu, L. Ungur, J. Liu, Q.-W. Li, L.-F. Wang, Z.-P. Ni, L. F. Chibotaru, X.-M. Chen and M.-L. Tong, J. Am. Chem. Soc., 2016, 138, 2829-2837.

24 Y.-S. Meng, L. Xu, J. Xiong, Q. Yuan, T. Liu, B.-W. Wang and S. Gao, Angew. Chem. Int. Edit., 2018, 57, 4673-4676.

25 J. Long, I. V. Basalov, N. V. Forosenko, K. A. Lyssenko, E. Mamontova, A. V. Cherkasov, M. Damjanović, L. F. Chibotaru, Y. Guari, J. Larionova and A. A. Trifonov, Chem. Eur. J., 2019, 25, 474-478.

26 J. Long, Y. Guari, R. A. S. Ferreira, L. D. Carlos and J. Larionova, Coord. Chem. Rev., 2018, 363, 57-70.

27 J. Long, Frontiers in Chemistry, 2019, 7, 63.

28 J.-H. Jia, Q.-W. Li, Y.-C. Chen, J.-L. Liu and M.-L. Tong, Coord. Chem. Rev., 2019, 378, 365-381.

29 F. Pointillart, B. le Guennic, O. Cador, O. Maury and L. Ouahab, Acc. Chem. Res., 2015, 48, 2834-2842.

30 D. Casanova, M. Llunell, P. Alemany and S. Alvarez, Chem. Eur. J., 2005, 11, 1479-1494.

31 Y. Ge, Y. Qin, Y. Cui, Y. Pan, Y. Huang, Y. Li, W. Liu and Y.-Q. Zhang, Chemistry - An Asian Journal, 2018, 13, 3753-3761.

32 T. J. Boyle, S. D. Bunge, P. G. Clem, J. Richardson, J. T. Dawley, L. A. M. Ottley, M. A. Rodriguez, B. A. Tuttle, G. R. Avilucea and R. G. Tissot, Inorg. Chem., 2005, 44, 1588-1600.

33 K. R. Meihaus, S. G. Minasian, W. W. Lukens, S. A. Kozimor, D. K. Shuh, T. Tyliszczak and J. R. Long, J. Am. Chem. Soc., 2014, 136 6056-6068.

34 N. F. Chilton, D. Collison, E. J. L. McInnes, R. E. P. Winpenny and A. Soncini, Nat. Commun., 2013, 4, 2551. 